\title{
Chemical Activity of Gamma-Irradiated Polymethyl Methacrylate ${ }^{1}$
}

\author{
Leo A. Wall and Daniel W. Brown
}

\begin{abstract}
In studies of polymerization and depolymerization with $\gamma$-irradiated polymethyl methacrvlate, effects were observed indicative of long-lived free radicals in the solid polymer. With a dose of $10^{7}$ roentgens, the free-radical concentration, as measured by both types of experiments, is estimated to be at least $10^{-5}$ mole per liter. When irradiated in air the polymer contains peroxide structures of at least $10^{-3}$ mole per liter concentration. The decomposition of these peroxidic groups is accelerated by tert-butyl catechol and is associated with the production of scissions in the polymer chain.
\end{abstract}

\section{Introduction}

Considerable evidence $[1,2]^{2}$ has been reported for the presence of radicals in frozen materials, held at about $90^{\circ} \mathrm{K}$ and irradiated with some type of irradiation, either ionizing or ultraviolet. In addition, it has been reported that polymerizations producing gelled material leave trapped considerable concentrations of radicals, up to $10^{-3}$ mole per liter [3]. Recent paramagnetic resonance studies [4] have demonstrated the existence of free radicals in previously X-irradiated plastics. These experiments were carried out at room temperature.

The work reported herein was undertaken for the purpose of demonstrating by chemical means the presence of immobilized free radicals, and of determining something of the nature of the various structures produced in solid polymers by $\gamma$-radiation. Furthermore, it is hoped that the results will help elucidate the mechanism of radiation effects in plastics.

\section{Experimental Procedure}

Methyl methacrylate and styrene monomers were obtained from the Rohm \& Haas and Dow Chemical Companies, respectively. Both monomers were flash-distilled at about $35^{\circ} \mathrm{C}$ immediately before use in order to remove inhibitors. Only about 50 percent of the monomer was distilled; the residues were discarded.

Hydroquinone and benzoquinone were chemically pure grades obtained from Fisher Scientific Co. The tert-butyl catechol was a technical grade obtained from Eastman. Kodak.

The polymer used for irradiation was prepared in 12-percent conversion. from twice-degassed methyl methacrylate at $60^{\circ} \mathrm{C}$, using 0.0082 mole per liter of benzoyl peroxide. It was precipitated with methanol and dissolved in benzene three times. The third benzene solution contained about 5 weightpercent of polymer; it was frozen, and the benzene was sublimed off in a vacuum. The residue was

${ }_{1}^{1}$ Presented at the 127th Meeting of the American Chemical Society, Cincinnati, Ohio, March 29 to April 7, 1955.

2 Figures in brackets indicate the literature references at the end of this paper. heated for 10 days at $60^{\circ} \mathrm{C}$ in a vacuum oven. Its intrinsic viscosity in benzene at $29.3^{\circ} \mathrm{C}$ was 1.66 .

Each irradiation tube contained $0.2000 \pm 0.0005 \mathrm{~g}$ of the above material. Before exposure, each tube was heated at $100^{\circ} \mathrm{C}$ for $20 \mathrm{hr}$ on a high-vacuum line. After cooling, the samples to be irradiated in a vacuum were sealed off; the others were removed and stoppered

Most of the irradiations were performed at the Naval Research Laboratory, Washington, D. C. The NRL source has been described [5]. The tubes were exposed in the inner cell in a holder that kept them in 1-cm annular rings within the cell. The polymer samples were each distributed through a cylindrical volume 0.8 -cm diameter by $1.5 \pm 0.2 \mathrm{~cm}$ high. The dose rates calculated were those at the center of each annular ring at the average height of the centers of the polymer samples. Individual polymer samples received doses different from those calculated because of variations in the height of the sample and variations in the dose rate around each annular ring. It is estimated that such variations amount to about 5 percent.

The irradiations reported in figure 6 were performed with a 200-curie cobalt-60 source at the Bureau. This is a single piece of cobalt, and as the samples were positioned very close to it, the doses reported are orders of magnitude only. These samples weighed about $0.035 \mathrm{~g}$ each and were prepared as described above.

The drop in viscosity with time after addition of tert-butyl catechol (fig. 3) was studied by adding the catechol to a solution of the air-irradiated polymer in a Ubbelohde viscometer and by measuring the viscosity at different times.

To test samples as low-temperature polymerization initiators the tubes were scratched lightly with a file and placed in viscometers like that sketched in figure 1 . The viscometer was tipped, causing the sample tube to move into side arm D; side arm C could then be closed off at the dotted line without pyrolyzing the polymer. After cooling, the sample tube was returned to side arm C. If desired, inhibitor was added in benzene solution, and the viscometer was evacuated to dryness. Freshly distilled monomer was then pipeted into the vessel through A, and a glass-encased piece of iron was 


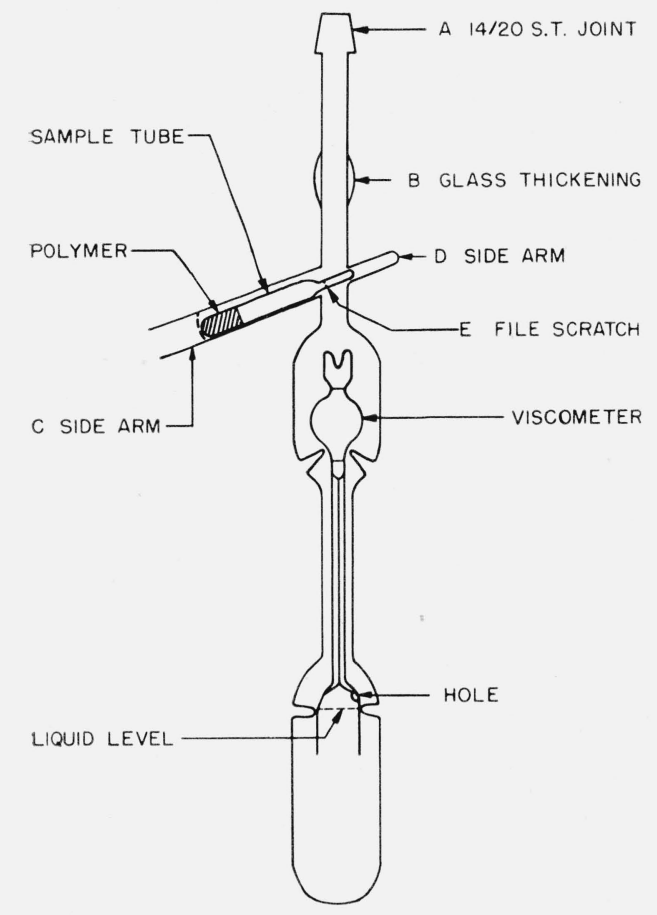

Figure 1. Viscometer for the study of the effect of $\gamma$-irradiated polymer in initiating polymerization.

placed gently on the tip of the sample tube, and the viscometer was waxed into a vacuum line at $A$. The monomer was degassed by freeze-evacuate-melt cycles. During the third evacuation the iron weight was raised with a magnet and dropped on the tip of the sample tube, which broke at E. After the gases in the sample tube were pumped out and the pressure had been reduced to about $10^{-4} \mathrm{~mm} \mathrm{Hg}$, the iron weight was raised by a magnet, and the viscometer was sealed off at $B$. The viscometer was then immersed in the $29.3^{\circ} \mathrm{C}$ bath and the sample dissolved by pouring monomer on and off the polymer. Time was measured from the instant of immersion; the polymer seemed to dissolve within 25 to $30 \mathrm{~min}$. The viscosity was measured by inverting the tube to fill the viscometer, reinverting it, and timing the flow. Kinetic-energy corrections were made.

In some of the early work, attempts were made to distill monomer directly into the viscometer tubes, but the amount of monomer could not be accurately controlled.

The polymerizations at $70^{\circ} \mathrm{C}$ were performed in apparatus like that sketched in figure 2. After closing off the sidearm at the dotted line, monomer was pipeted into container $\mathrm{D}$, the system was degassed, the polymer tube opened, and the system sealed off at $\mathrm{B}$ as before. The polymer was dissolved at room temperature and poured into $\mathrm{G}$ through the capillary. The whole device was then placed in a $70^{\circ} \mathrm{C}$ oil bath. Time was measured from the instant the solution stopped flowing from the capillary into D. Because the dilatometer was calibrated from $\mathrm{H}$ to $\mathrm{F}$, as well as below $\mathrm{F}$, poly-

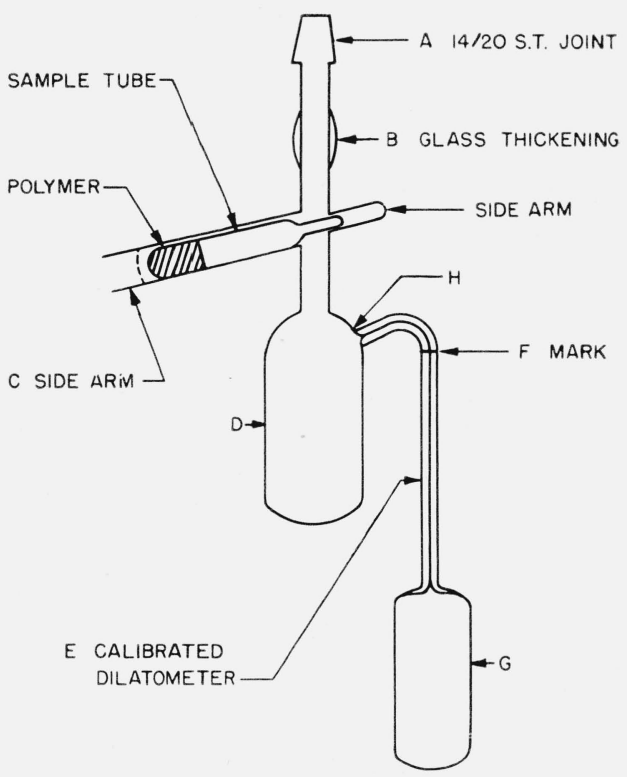

Figure 2. Dilatometer for the study of the effect of $\gamma$-irradiated polymer in initiating polymerization.

merization could be measured by recording the time it took for the meniscus to reach $\mathrm{F}$ and then following the drop of the meniscus with a cathetometer. This procedure made possible the use of fine capillaries, so that 1 percent of polymerization resulted in a 4- to 5-cm change in the position of the meniscus. The volume from $\mathrm{F}$ to $\mathrm{H}$ was small, equivalent to about 0.3 percent of conversion.

\section{Results}

\subsection{Tert-Butyl Catechol Effect}

In an earlier investigation it had been noted [6] that irradiated polymethyl metbacrylate and polystyrene had measurably lower intrinsic viscosities when dissolved in benzene containing 0.05 percent of tert-butyl catechol than when dissolved in pure benzene. The object of measuring intrinsic viscosities of samples dissolved in inhibitor-containing solvents was to obtain evidence for immobilized free radicals. The concept was as follows. If radicals in an irradiated polymer combine when the material is dissolved in benzene, a certain intrinsic viscosity would be observed. Dissolving the same material in a benzene solution containing an effective monofunctional terminator should then result in the observation of a somewhat lower intrinsic viscosity. Of course, if the radicals terminated by disproportionation, then no difference in viscosities would be observed. For detection in this manner, greater than $10^{-4}$ mole per liter of recombining radicals would be necessary.

In this work, experiments on polymethyl methacrvlate irradiated in a vacuum showed no detectable differences. However, the effect was observed on samples irradiated in the presence of air. Furthermore, on adding tert-butyl catechol to the polymer 


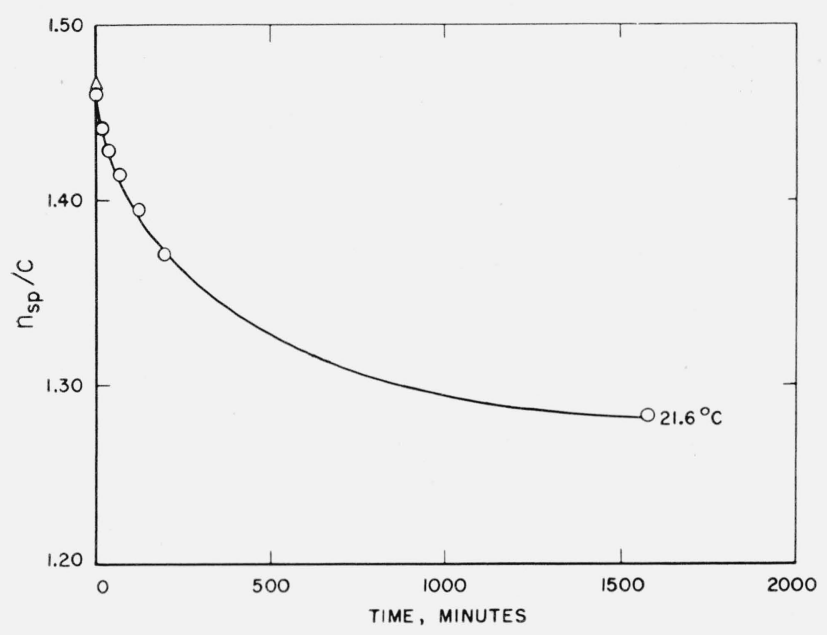

Figure 3. Viscosity decrease of a benzene solution of irradiated polymethyl methacrylate after addition of 0.0280 tert-butyl catechol.

Dose about $10^{7} \mathrm{r}$.

solution, the viscosity of the solution was observed to drop slowly over a period of several hours. Figure 3 shows a typical curve at $21.6^{\circ} \mathrm{C}$. These results appear to indicate a labile structure, probably a peroxide type, the decomposition of which leads to or involves a scission of the polymer chains. The decomposition process is also evidently promoted by tert-butyl catechol. Several other possible promoters were tried. Those that were effective were hydroquinone and dimethyl aniline, whereas benzoquinone, phenol, and diphenyl picryl hydrazine produced negligible effects. The changes observed in the flow times amounted to about 20 sec out of 350 . With unirradiated polymer, the presence of inhibitors raises the flow times only slightly.

\subsection{Polymerization Near Room Temperature}

A second test for free radicals was the effect of irradiated polymer in producing polymerization at temperatures below those usually required for peroxide decomposition. A temperature of $29^{\circ} \mathrm{C}$ was used, which should be adequate for the propagation of radicals already formed. However, when polymethyl methacrylate has not been $\gamma$-irradiated it is known to have some catalytic activity for polymerization [7]. This activity is removed by heating the polymer [8]. Most of the polymethyl methacrylate was therefore heated prior to the various experiments for $20 \mathrm{hr}$ at $100^{\circ} \mathrm{C}$ in a vacuum. Such polymer is referred to as deactivated. The technique for preparing tubes for measurement of viscosity changes was described above, see figure 1 .

In figure 4 the catalytic activity of $\gamma$-irradiated polymer is shown compared with nonirradiated material and also with nonirradiated material with an added trace of benzoquinone. It is evident that irradiation has considerable, although not impressive, effect. The induction period for the nonirradiated

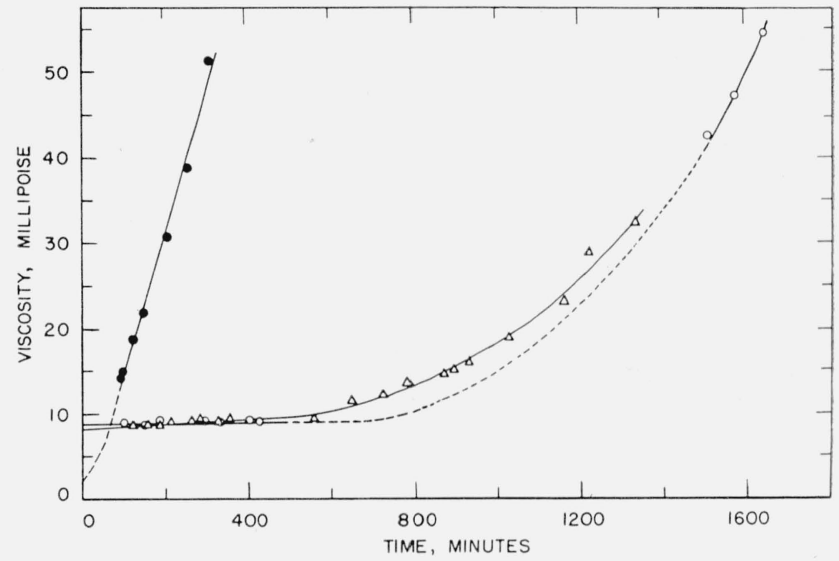

Figure 4. Polymerization of methyl methacrylate in the presence of deactivated polymer.

Initial concentration $0.4 \mathrm{~g} / 100 \mathrm{~cm}^{3}$, at $29.3^{\circ} \mathrm{C}$

$\triangle$, Not irradiated; $O$, not irradiated, containing $0.13 \times 10^{-6} \mathrm{~g} /$ liter of benzoquinone; $\boldsymbol{O}$, irradiated $2 \times 10^{7} \mathrm{r}$.

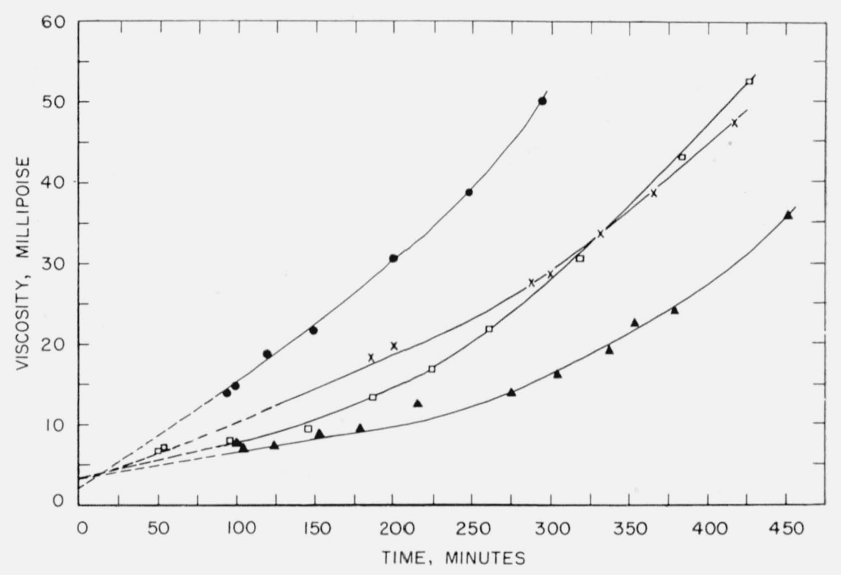

Figure 5. Polymerization of methyl methacrylate in the presence of $\gamma$-irradiated polymethyl methacrylate at $29^{\circ} \mathrm{C}$.

Storage time, 1 week, all samples deactivated initially.

Irradiated $2 \times 10^{7} \mathrm{r}$, stored in vacuum; $\triangle$, irradiated $10^{7} \mathrm{r}$, stored in air; $\mathrm{x}$, irradiated $10^{7} \mathrm{r}$, stored in vacuum, containing $1.3 \times 10^{-8} \mathrm{~g} / 100 \mathrm{~cm}^{3}$ of quinone; $\square$, irradiated $10^{7} \mathrm{r}$, stored in vacuum, containing $3.3 \times 10^{-8} \mathrm{~g} / 100 \mathrm{~cm}^{8}$ of quinone.

material is believed due to traces of oxygen not removed by the vacuum pumping. It is seen that the oxygen inhibition is equivalent to an appreciable quantity of quinone.

In figure 5 the retarding effect of quinone on the polymerization in the presence of irradiated polymer is shown. The effect of air exposure on a polymer previously exposed to radiation in a vacuum is shown to give a considerable reduction to the activity of the irradiated polymer. Neither storage for 7 days nor the amount of inhibitor used was sufficient to annihilate the activity due to $\gamma$-irradiation (compare figs. 4 and 5). In subsequent polymerization studies at $70^{\circ} \mathrm{C}$, exposure of irradiated polymers to air resulted in a catalytic effect. 


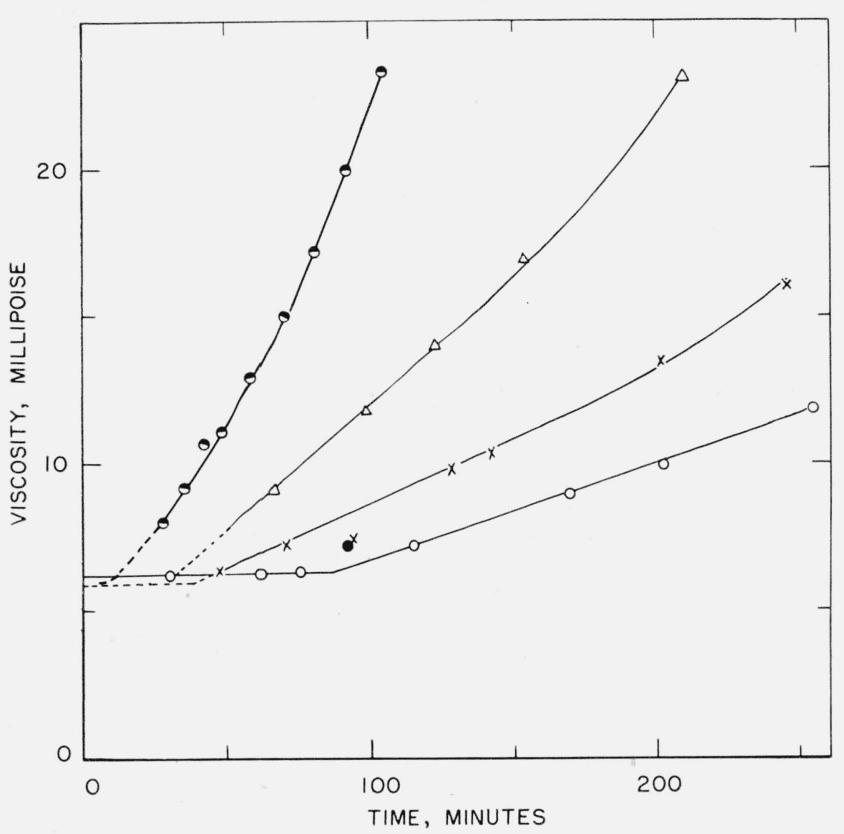

Figure 6. Polymerization of methyl methacrylate in presence of polymethyl methacrylate at $29^{\circ} \mathrm{C}$.

๑, Deactivated, irradiated $10^{7} \mathrm{r}$, initial polymer concentration $1.65 \mathrm{~g} /$ liter; $\triangle$, undeactivated, not irradiated, initial polymer concentration $1.25 \mathrm{~g} / \mathrm{liter} ; \mathrm{x}$, deactivated, irradiated $10^{7} \mathrm{r}$, containing hydroquinone $0.058 \mathrm{~g} /$ liter, initial polymer concentration $1.25 \mathrm{~g}$ /liter; $\bigcirc$, undeactivated, not irradiated, containing hydroquinone $0.058 \mathrm{~g}$ /liter, initial polymer concentration $1.25 \mathrm{~g}$ /liter; 0 . No polymer present.

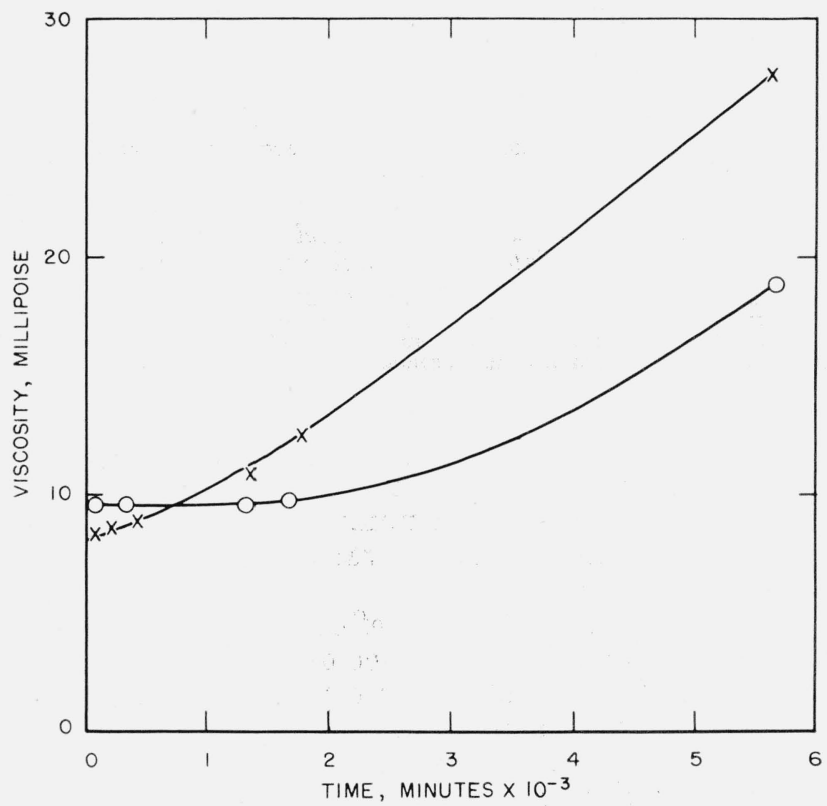

Figure 7. Polymerization of styrene in the presence of deactivated polymethyl methacrylate at $29^{\circ} \mathrm{C}$.

$\times$, Irradiated $3 \times 10^{7} \mathrm{r}$, initial polymer concentration $1.37 \mathrm{~g} /$ liter; $\bigcirc$, not irradiated, initial polymer concentration $1.37 \mathrm{~g} /$ liter.
Irradiation, as shown in figure 6, produced som catalytic effect compared with undeactivated nonirradiated polymer. Parallel runs with a small amount of hydroquinone added show similar behavior, that is, that undeactivated nonirradiated polymer is somewhat less active than irradiated deactivated polymer.

The intercepts in these figures were estimated from the intrinsic viscosities in benzene of polymer samples irradiated under the same conditions.

The results of two experiments in which styrene monomer was polymerized in the presence of irradiated and nonirradiated polymethyl methacrylate are shown in figure 7 . The polymerization behavior observed is similar to that in figure 3 , except that styrene is slower to polymerize than methyl methacrylate. Again, the irradiated polymer shows greater activity than the unirradiated.

\subsection{Polymerization at $70^{\circ} \mathrm{C}$}

In order to obtain further evidence for storage of radicals in irradiated polymethyl methacrylate, a series of experiments was carried out by using sensitive dilatometers at $70^{\circ} \mathrm{C}$. This temperature was chosen in order that the activity due to peroxides formed in the polymer would be effective. It was anticipated that the free-radical effect would be magnified by exposure to air of the polymer irradiated in a vacuum, i. e., to oxygen through the formation of peroxides. It is reasonable to expect that considerably more peroxide groups would be formed

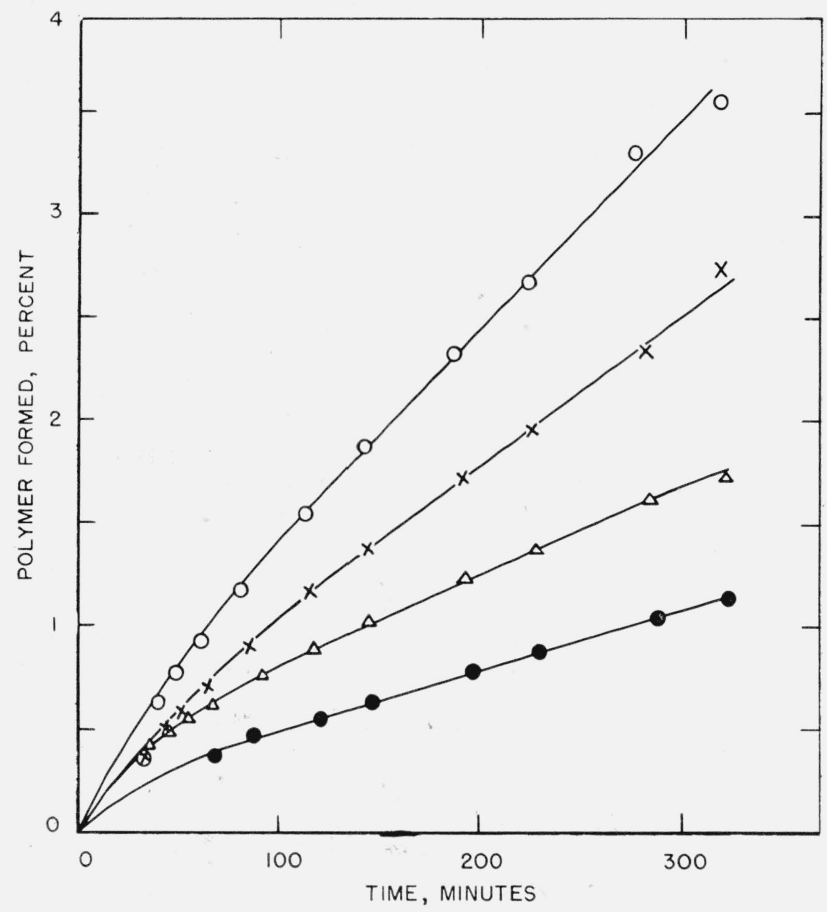

Figure 8. Polymerization of methyl methacrylate monomer catalyzed by 1 percent deactivated polymethyl methacrylate at $70^{\circ} \mathrm{C}$.

Storage time, 1 week

, Polymer irradiated in air, $10^{7} \mathrm{r}$, stored in air; $\mathrm{x}$, polymer irradiated in vacuum, $10^{7} \mathrm{r}$, stored in air; $\triangle$, polymer irradiated in vacuum, $10^{7} \mathrm{r}$, stored in vacuum; , polymer not irradiated, used immediately after deactivation. 
than radicals present after irradiation. Hence a greater activity for polymerization should be observed at $70^{\circ} \mathrm{C}$ with irradiated polymer stored in air. Previously it was demonstrated, figure 5, that polymerization at $29.3^{\circ} \mathrm{C}$ was curtailed by storage in air. The results shown in figure 8 support the concept described, a greater rate of polymerization occurring when irradiated polymer was exposed to air. Of course, irradiation in air produced an even greater effect.

\subsection{Depolymerization of Irradiated Polymer}

It has been suggested that the foaming [9] in polymethyl methacrylate observed when previous irradiated polymer is heated is due to the expansion of gases formed during the irradiation at a lower temperature. Another possibility is that radicals produced during the irradiation depropagate to produce monomer, which may also cause bubble formation.

In table 1 the results of some experiments to test this hypothesis are given. All samples of polymethyl methacrylate studied were in a finely divided form and were deactivated by a prior heating in a vacuum for $20 \mathrm{hr}$ at $100^{\circ} \mathrm{C}$. After the treatment indicated in table 1 the volatile products were analyzed by means of a mass spectrometer. It is seen that irradiation alone produces relatively small amounts of gases, most of which are the result of radiolysis of the ester groups in the polymer. It is noted that in this case no monomer was detected.

Without prior irradiation, heating alone produced some monomer. The benzene observed comes from the solvent, which was used in the preparation of the samples, still remaining in the polymer. It is estimated from this yield that the polymers contained at least 2 percent of benzene. The trace of hydrogen is somewhat surprising in view of the fact that the material had not been irradiated. This is also partially true of the fact that more hydrogen was produced from the irradiated and heated samples than from the irradiated unheated sample.

When heated after irradiation more monomer is produced, and if the irradiation is carried out in the presence of air, an even larger quantity of monomer is produced. The benzene decreases slightly, which may indicate some radiolysis of this solvent.

TABLE 1. Volatile products obtained from $\gamma$-irradiated polymethyl methacrylate

(In moles $\times 10^{3} / \mathrm{kg}$ of polymer.)

\begin{tabular}{|c|c|c|c|c|}
\hline \multirow{2}{*}{ Product } & \multicolumn{4}{|c|}{ Treatment given polymer ${ }^{a}$} \\
\hline & ${ }^{b} \mathrm{I}_{\mathrm{yac}}$ & ${ }^{\circ} \mathrm{H}$ & $\mathrm{I}_{\mathrm{vac}}, \mathrm{H}$ & ${ }^{b} \mathrm{I}_{\mathrm{air}}, \mathrm{II}$ \\
\hline Hydrogen & 1. 37 & 0.78 & 4. 67 & $\begin{array}{r}5.5 \\
16\end{array}$ \\
\hline $\begin{array}{l}\text { arbon dioxide } \\
\text { Methyl formate }\end{array}$ & $\begin{array}{l}2.07 \\
0.57\end{array}$ & …. & 7.9 & 16.2 \\
\hline Carbon monoxide & 2.83 & .... & ….... & ...... \\
\hline Methane & 3.56 & & 64 & \\
\hline Methyl methacrylate & 0.0 & 11.7 & 45.6 & 152 \\
\hline Benzene _..._. & .06 & 246 & 227 & 222 \\
\hline
\end{tabular}

a All polymer samples were previously deactiviated by heating $20 \mathrm{hr}$ at $100^{\circ} \mathrm{C}$. ${ }^{b} \mathrm{I}_{\mathrm{vac}}$, Irradiated in vacuum, dose $3.9 \times 10^{20} \mathrm{ev} / \mathrm{g} ; \mathrm{I}_{\mathrm{air}}$, irradiated in air, dose $3.9 \times 10^{20} \mathrm{ev} / \mathrm{g} ; \mathrm{H}$, heated $3 \mathrm{hr}$ at $125^{\circ} \mathrm{C}$

\section{Discussion}

The viscosity decrease observed when tert-butyl cathechol is added to solutions of polymers which were irradiated in air, is tentatively believed to be the result of a peroxide structure, the decomposition of which leads to or involves a scission of the polymer chain: From the viscosity changes and by assuming one scission is equivalent to a peroxide structure it is estimated that at least $10^{-3}$ mole per liter of such structures were produced for an irradiation of $10^{7} \mathrm{r}$.

The number of radicals in the polymer irradiated in a vacuum was estimated in several ways. From the data in figures 4 and 5 it can be assumed that the air inhibition is equivalent to about $3.3 \times 10^{-6} \mathrm{~g}$ of benzoquinone per liter of monomer and that each benzoquinone molecule captures two radicals. This leads to a radical concentration in the polymer after irradiation of $1.5 \times 10^{-5}$ mole of radicals per liter. This value is probably a minimum since during the dissolving process many of the radicals may selfterminate.

From the data on monomer vield presented in table 1, the radical concentration was estimated assuming that each radical depropagates to the end of a molecule producing monomer. Hence the radical concentration is approximately the yield of monomer based on a liter of polymer divided by the degree of polymerization. After irradiation the degree of polymerization is $3 \times 10^{3}$. After correcting for the monomer yield from the nonirradiated polymer the radical concentration as estimated from the depolymerization data is $(45.6-11.7) 10^{-3} / 3 \times$ $10^{3}=1.2 \times 10^{-5}$ mole per liter, which is probably a low estimate also. These concentrations are not too different from those reported from paramagnetic resonance studies [4].

It is unlikely that very large effects can be produced in polymerization experiments of the type described because of the rapid termination of radicals in solution. The time for a hundredfold decay of methyl methacrylate radicals in monomer solution, using $10^{7}$ liters mole ${ }^{-1} \mathrm{sec}^{-1}$ [10] for the rate of termination, is given by $t=10^{2} / 10^{7} R_{0}$. If the initial radical concentration, $R_{0}$, is $10^{-5}$ mole per liter, then only 1 sec elapses before the radical concentration drops to $10^{-7}$ mole per liter.

Such decay times for radicals in the solid polymer can also be estimated, using for the termination rate constants at various temperatures, values obtained from the relation $k_{t}=3 \times 10^{14} e^{-20,000 / R T}$ liters mole ${ }^{-1}$ $\sec ^{-1}[10]$. At the temperature used in the depolymerization the hundredfold decay time is estimated to be $17 \mathrm{~min}$, for an initial radical concentration of $10^{-5}$ mole per liter. It can also be estimated from the depropagation rate constant of Cowley and Melville [11] that one-half of a polymer molecule would require $19 \mathrm{sec}$ for complete decomposition to monomer. Thus it would appear that depropagation of most of the polymer radicals to the end of their chains would occur before termination and the method of calculation based on depolymerization appears reasonable for rough estimates. At the end 
of 19 sec about 60 percent of the original $10^{-5}$ mole per liter concentration of radicals would remain, provided no complete depropagation occurred.

At room temperature the rate of termination is approximately unity, and $10^{-5}$ mole per liter of radicals would require about 4 months to decay to a concentration of $10^{-7}$ mole per liter. The experiments presented were carried out from days to several weeks after the irradiation of the polymers. No attempt was made to measure the decay time in the solid polymers at room temperature because of the small magnitude of the effects observed and because of the tedious and complicated nature of the experiments. For instance, merely aging the polymers in air at room temperature tends to reactivate them. The results with undeactivated polymer suggests that during storage oxidative processes lead to small concentrations of free radicals in the polymer.

Perhaps the best indications of radical activity are the results obtained with polymers irradiated in vacuum and subsequently exposed to air. The inhibition observed at $29^{\circ} \mathrm{C}$ suggests that the oxygen assisted in terminating a good fraction of the radicals with the formation of peroxides which catalyzed polymerization at $70^{\circ} \mathrm{C}$.
The authors express their appreciation to J. I. Schulman, Wm. Price, J. Willis, and Lee Johnson of the Naval Research Laboratory, and to T. Loftus of the Radiological Equipment Section of the Bureau for assistance in irradiating the material.

\section{References}

[1] T. V. Schmitz and E. J. Lawton, Science 113, 718 (1951).

[2] I. Normand and G. Porter, Nature 174, 508 (1954).

[3] G. K. Fraenkel, J. M. Hirshon, and C. Walling, J. Am. Chem. Soc. $\boldsymbol{7 6}, 3606$ (1954).

[4] E. E. Schneider, Micro wave and radiofrequency spectroscopy, Discussions Faraday Soc., No. 19, p. 158, (1955).

[5] H. Rabin and W. E. Price, Nucleonics 13, 33 ( 1955).

[6] L. A. Wall and M. Magat, J. chim. phys. 50, 308 (1953).

[7] H. W. Melville and W. F. Watson, J. Polymer Sci. 11, 299 (1953)

[8] I. Waltcher, J. Polymer Sci. 14, 411 (1954).

[9] A. Charlesby and M. Ross, Nature 171, 1153 (1953).

[10] H. W. Melville and G. M. Burnett, J. Polymer Sci. 13, 417 (1954).

[11] P. R. E. J. Cowley and H. W. Melville, Proc. Roy. Soc. [A] $\mathbf{2 1 1}, 320(1952)$.

Washington, May 2, 1956. 